\title{
Mixed Convection Heat Transfer in a Partially Heated Parallel Plate Vertical Channel
}

\author{
Hasan Celik, Moghtada Mobedi \\ Izmir Institute of Technology, \\ Department of Mechanical Engineering, \\ Urla 35430 Izmir, Turkey \\ Email: hasancelik@iyte.edu.tr ; moghtadamobedi@iyte.edu.tr
}

\begin{abstract}
Laminar mixed convection heat transfer in a two dimensional symmetrically and partially heated vertical channel is investigated. The heated portions exist on the both walls of channel and their temperature is constant. The number of the heated portions is changed from 2 to 4 for each wall; however the total length of the heated portions is fixed. The fluid inlet velocity is uniform and air is taken as working fluid. The continuity, momentum and energy equations are solved numerically by using finite volume method. Results are compared with available studies in literature and good agreement is observed. The velocity and temperature fields are obtained for $\mathrm{Gr} / \mathrm{Re}^{2}=0.0033$ and 13.33. Based on the obtained temperature distributions, the change of local Nusselt number for different number of heated portions are obtained and plotted. The variation of the mean Nusselt number with the number of heated portions is also discussed.
\end{abstract}

KEY WORDS: partial heating, mixed convection, parallel plate channel

\section{NOMENCLATURE}

g acceleration due to gravity $\mathrm{m} / \mathrm{s}^{2}$

$\mathrm{Gr} \quad$ Grashof number for channel with clear fluid

$\mathrm{h}$ convective heat transfer coefficient, $\mathrm{W} / \mathrm{m}^{2} \mathrm{~K}$

$\mathrm{H} \quad$ length of parallel plates, $\mathrm{m}$

$\mathrm{k}$ thermal conductivity, $\mathrm{W} / \mathrm{mK}$

$\mathrm{Nu} \quad$ Nusselt number defined in Eq. 14

$\overline{N u} \quad$ Mean Nusselt number defined in Eq. 15

$\mathrm{p}$ pressure, $\mathrm{Pa}$

$\mathrm{P} \quad$ dimensionless pressure

Re Reynolds number

$\mathrm{T}$ temperature, ${ }^{\circ} \mathrm{C}$

$\mathrm{u}, \mathrm{v} \quad$ axial and transverse velocity, $\mathrm{m} / \mathrm{s}$

$\mathrm{U}, \mathrm{V}$ dimensionless axial and transverse velocity

$\mathrm{x}, \mathrm{y}$ axial and transverse coordinate, $\mathrm{m}$

$\mathrm{X}, \mathrm{Y}$ dimensionless axial and transverse coordinate

W spacing between walls, $\mathrm{m}$

\section{Greek Symbols}

$\alpha$ thermal diffusivity, $\mathrm{m}^{2} / \mathrm{s}$

$\beta \quad$ coefficient of thermal expansion, $1 / \mathrm{K}$

$\theta \quad$ dimensionless temperature

$v \quad$ kinematic viscosity of the fluid, $\mathrm{m}^{2} / \mathrm{s}$

$\rho$ density, $\mathrm{kg} / \mathrm{m}^{3}$

$\tau \quad$ dimensionless time

\section{Subscripts}

i, o inlet

w wall

\section{INTRODUCTION}

Mixed convection in heated channels has received attention of researchers due to its application in many industrial areas such as nuclear reactors, cooling of electronic equipment and heat exchangers. For a fixed fluid flow rate into a vertical channel, the buoyancy effects result in flow reversals in the middle of the channel since fluid in the region near the hot wall receives an extra force (buoyancy force).

Mixed convection in vertical channels with discrete heat source was studied by Turkoglu and Yucel [1]. They considered two dimensional laminar mixed convection flow in a vertical channel with a discrete heat source, numerically. A heat source with negligible thickness is located on the adiabatic wall while the other wall of the channel is isothermal. A uniform heat flux was imposed to the surface of heat source. They found that the location of the heat source on Nusselt number and maximum temperature is negligible except the case in which heat source is located in the entrance region. The Nusselt number is higher for the cases in which heat source is located in the entrance region. A laminar two dimensional and opposing mixed convection flow with nonadiabatic walls on which isothermal discrete heat source exits was studied by Suestegui and Trevino [2]. The time dependence average Nusselt number was defined and its variation through heating process was analyzed. Elpidorou et al. [3] studied two-dimensional steady free and forced convection from a flush mounted isoflux heat source on one vertical wall while the other wall is adiabatic. The thickness of the heat source is neglected. They found that in the free convection regime, the flow may separate from the unheated wall at high Grashof number and if the channel is long, it may reattach at a high distance far away from the heat source. Mixed convection in a vertical channel with two discrete heat sources at the wall were studied by Ermolaev and Zhbanov [4]. Discrete heat sources are located on the one adiabatic wall and the other wall is also adiabatic in their study. They concluded that the increase distance between the local heating sources results the decreasing of secondary flow intensity. The thickness of the heat source was also neglected. The effects of mixed convection heat transfer inside a vertical channel at low Peclet numbers on heat transfer mechanism was studied by Chow et al. [5]. The walls of the inlet and outlet sections of the channel are insulated and heated plated are placed between the insulated walls. They concluded that the effect of axial conduction is significant at low Peclet numbers but this effect is greater in the case of cooling.

One of aims of thermal engineers in cooling of the conventional electronic equipment is to cool high powered electronic components with minimum air flow rate and 
pressure drop (i.e. smaller fan power). Reducing the power of fan decreases the size of electronic device and noises. The decrease of air flow rate causes the mechanism of the heat transfer in the electronic devices is changed from forced to mixed convection. Our literature survey showed that number of reported studies on mixed convection heat transfer in vertical channels is limited particularly for the channels with partially heated walls. In this study, heat transfer in a vertical channel which is symmetrically and partially is cooled analyzed. The heat sources have negligible thickness located on the insulated walls of the channel. The study performed for completely heated and three partially heated cases. The temperature and velocity distributions are obtained numerically and plotted for two values of $\mathrm{Gr} / \mathrm{Re}^{2}$ numbers as 0.0033 and 13.33. Furthermore, the local and average Nusselt numbers are calculated and their variations with number of the heated sources are discussed.

\section{THE CONSIDERED PROBLEM}

Mixed convection in the vertical channel shown in Fig. 1 is studied. The fluid flowing through the channel is assumed to be Newtonian and incompressible, while the flow is laminar, and steady. The walls of the channel are divided into periodic heated and non-heated sections and those heated sections are maintained at constant temperature of $\mathrm{T}_{\mathrm{w}}$. The channel has a rectangular cross-section with width of $\mathrm{w}$ and $\mathrm{H}$ is the length of the channel. It is assumed that the plates are infinitely long in depth direction; the fluid flows in y direction (longitudinal direction) while $\mathrm{x}$ is perpendicular to the flow direction (transverse direction). The fluid properties are assumed to be constant except the density in buoyancy term of the momentum equation. Viscous dissipation and radiation heat transfer are neglected and gravity acts in $-\mathrm{y}$ direction.

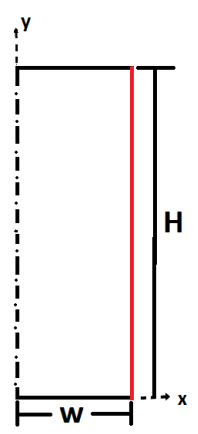

(a)

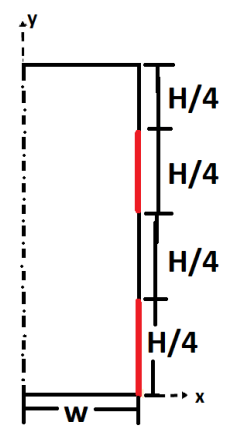

(c)

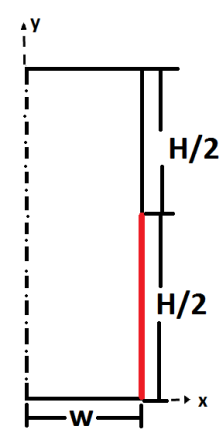

(b)

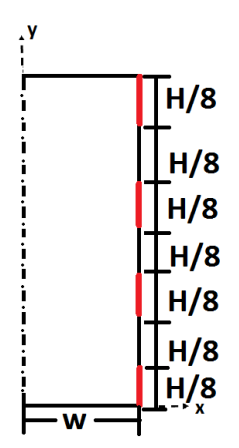

(d)
Figure 1: The studied channels a) completely heated wall, b) channel with one heated portion c) channel with two heated portions d) channel with four heated portions

\section{GOVERNING EQUATIONS AND BOUNDARY CONDITIONS}

The governing equations which are continuity, momentum in $\mathrm{x}$ and $\mathrm{y}$ directions and energy equations are given below both in dimensional and dimensionless form.

\section{Dimensional Form of the Governing Equations and Boundary Conditions}

Dimensional continuity, momentum in $\mathrm{x}$ and $\mathrm{y}$ directions and energy equations for two-dimensional, laminar mixed convection in a vertical channel under Boussinesq approximation can be expressed as:

$$
\begin{aligned}
& \frac{\partial u}{\partial x}+\frac{\partial v}{\partial y}=0 \\
& \frac{\partial u}{\partial t}+u \frac{\partial u}{\partial x}+v \frac{\partial u}{\partial y}=-\frac{1}{\rho} \frac{\partial p}{\partial x}+v\left(\frac{\partial^{2} u}{\partial x^{2}}+\frac{\partial^{2} u}{\partial y^{2}}\right) \\
& \frac{\partial v}{\partial t}+u \frac{\partial v}{\partial x}+v \frac{\partial v}{\partial y}=-\frac{1}{\rho} \frac{\partial p}{\partial x}+v\left(\frac{\partial^{2} u}{\partial x^{2}}+\frac{\partial^{2} u}{\partial y^{2}}\right)-g \beta\left(T-T_{i}\right) \\
& \frac{\partial T}{\partial t}+u \frac{\partial T}{\partial x}+v \frac{\partial T}{\partial y}=\alpha\left(\frac{\partial^{2} T}{\partial x^{2}}+\frac{\partial^{2} T}{\partial y^{2}}\right)
\end{aligned}
$$

The boundary conditions for the problem are:

$y=0 \quad T=T_{o} \quad u=u_{o} \quad v=0$

$y=H \quad \frac{\partial T}{\partial x}=\frac{\partial u}{\partial x}=\frac{\partial v}{\partial x}=0$

$x=0 \quad \frac{\partial T}{\partial x}=\frac{\partial u}{\partial x}=0 \quad v=0$

$x=w \quad u=v=0 ; \frac{\partial T}{\partial x}=0$ for wall and $T=T_{w}$ for heated partions

where $T_{o}$ and $u_{o}$ represents inlet temperature and velocity, respectively.

\section{Dimensionless Form of the Governing Equations and} Boundary Conditions

Dimensionless continuity, momentum in $\mathrm{x}$ and $\mathrm{y}$ directions and energy equations for the problem are:

$$
\begin{aligned}
& \frac{\partial U}{\partial X}+\frac{\partial V}{\partial Y}=0 \\
& \frac{\partial U}{\partial \tau}+U \frac{\partial U}{\partial X}+V \frac{\partial U}{\partial Y}=-\frac{\partial P}{\partial X}+\frac{1}{\operatorname{Re}}\left(\frac{\partial^{2} U}{\partial X^{2}}+\frac{\partial^{2} U}{\partial Y^{2}}\right) \\
& \frac{\partial V}{\partial \tau}+U \frac{\partial V}{\partial X}+V \frac{\partial V}{\partial Y}=-\frac{\partial P}{\partial Y}+\frac{G r \theta}{\operatorname{Re}^{2}}\left(\frac{\partial^{2} V}{\partial X^{2}}+\frac{\partial^{2} V}{\partial Y^{2}}\right) \\
& \frac{\partial \theta}{\partial \tau}+U \frac{\partial \theta}{\partial X}+V \frac{\partial \theta}{\partial Y}=\frac{1}{\operatorname{RePr}}\left(\frac{\partial^{2} \theta}{\partial X^{2}}+\frac{\partial^{2} \theta}{\partial Y^{2}}\right)
\end{aligned}
$$

where $\theta, \operatorname{Re}, \mathrm{Gr}$ numbers are defined as:

$\theta=\left(T-T_{o}\right) /\left(T_{w}-T_{o}\right) ; \operatorname{Re}=(2 u w) / v ;$

$G r=g \beta\left(T-T_{o}\right) w^{3} / v^{2}$.

Following dimensionless parameters are used in the above equations: 
$U=\frac{u}{u_{0}} \quad V=\frac{v}{v_{o}} \quad X=\frac{x}{w} \quad Y=\frac{y}{w} \quad \tau=\frac{t u_{0}}{w} \quad P=\frac{p}{\rho u_{0}^{2}}$

Dimensionless boundary conditions can be defined as:

$Y=0 \quad \theta=0, \quad U=1, \quad V=0$

$Y=H / w \frac{\partial \theta}{\partial X}=\frac{\partial U}{\partial X}=\frac{\partial V}{\partial X}=0$

$X=0 \quad \frac{\partial \theta}{\partial X}=\frac{\partial U}{\partial X}=0, \quad V=0$

$X=1 \quad U=V=0 ; \frac{\partial \theta}{\partial X}=0$ for wall and $\theta=1$ for heated partions

As can be seen from the Equations (6-8) and boundary conditions (Eq. 12) the solution depends on $\mathrm{Pr}, \mathrm{Re}, \mathrm{Gr} / \mathrm{Re}^{2}$, $\mathrm{H} / \mathrm{w}$ and number of heated portions whose length are equal to each other. In this study, the value of $\mathrm{H} / \mathrm{w}$ is equal to 16.67 (i.e. $\mathrm{H} / \mathrm{w}=16.67$ ) and $\mathrm{Re}$ is fixed as 300 . The study is performed for air with $\mathrm{Pr}=0.7$. Therefore, the variations of velocity and temperature, local and mean Nusselt number are discussed with $\mathrm{Gr} / \mathrm{Re}^{2}$ and number of heated portion (i.e. $\mathrm{n}$ ).

The local Nusselt number is calculated from the following relation:

$N u=-\frac{h w}{k}$

where heat flux at any point on the wall can be found as

$q^{\prime \prime}=-\left.k \frac{\partial T}{\partial x}\right|_{x=w}=h\left(T_{w}-T_{o}\right)$

and the mean Nusselt number for total heated portion with the length of $\mathrm{H} / 2$ is defined as:

$\overline{N u}=-\frac{\int_{0}^{H} N u d x}{H / 2}$

\section{SOLUTION METHOD}

In this study, the dimensional forms of governing equations are solved and then the results are made dimensionless by using Equations 10 and 11. Results in this study are obtained by using code based on finite volume method. The continuity, momentum and energy equations are solved by SIMPLE scheme. A uniform mesh is employed. Although, this paper focuses on steady state problem, time marching method is used and time step is taken as 0.1 seconds. The solution is considered to be converged when the maximum values of the residuals for each governing equation (i.e. continuity, momentum and energy equations) are less than $10^{-9}$.

A grid independence study is performed to ensure the accuracy of the study. The change of mean Nusselt number for a completely heated wall of vertical channel when $\mathrm{Gr} / \mathrm{Re}^{2}=$ 13.33 and $\mathrm{Re}=300$ with number of grid are obtained and presented in Figure 2. As it can be seen, by increasing number of mesh, the mean Nusselt number does not change. In this study, number of grid is $300 \times 600$ which is sufficient to obtain accurate result.
To verify the solution, the average Nusselt number for a channel in which only natural convection occurs is obtained and compared with the correlations of Ref. [6] as seen in Figure 3. In this correlation $\mathrm{Ra}^{\prime}$ is defined as:

$R a^{\prime}=\frac{\rho^{2} g \beta C_{p} w^{4} \Delta T}{\mu H}$

As can be seen, there is a good agreement between our results and correlation of Ref. [6].

\section{RESULTS AND DISCUSSION}

The changes of mean Nusselt number of the channels with mixed convection, whose both walls are completely heated, when the aspect ratio of the channel is 16.67 and $\mathrm{Re}=300$ is shown in Figure 4. As it can be seen from the Figure 4, the mean Nusselt number is constant for forced convection as $\mathrm{Nu}$ $=2.38$, however for mixed convection, the mean Nusselt number increases with increase of Grashof number. For low values of $\mathrm{Gr} / \mathrm{Re}^{2}$ the mean Nusselt number for forced and mixed convection are close to each other since forced convection is dominant. By increase of $\mathrm{Gr}$ number, the buoyancy effect increases and the difference between mean Nusselt numbers of forced and mixed convection becomes greater.

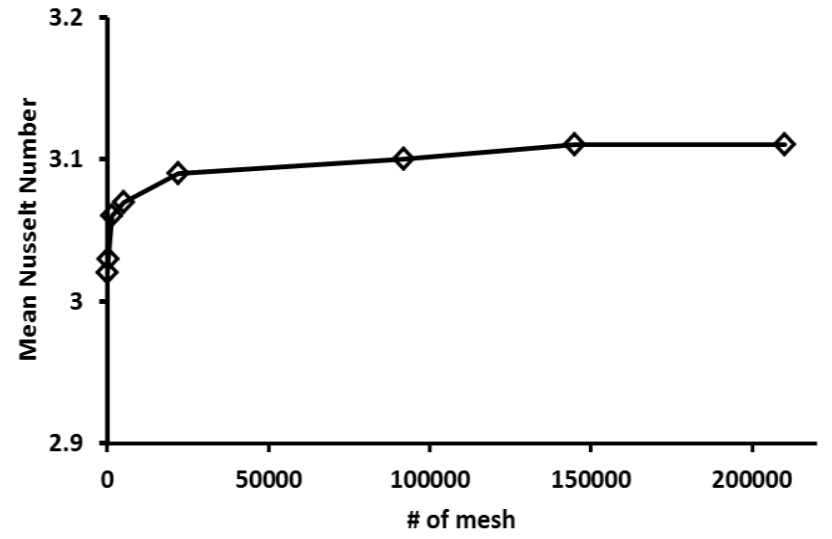

Figure 2: The effect of grid size on the obtained numerical results

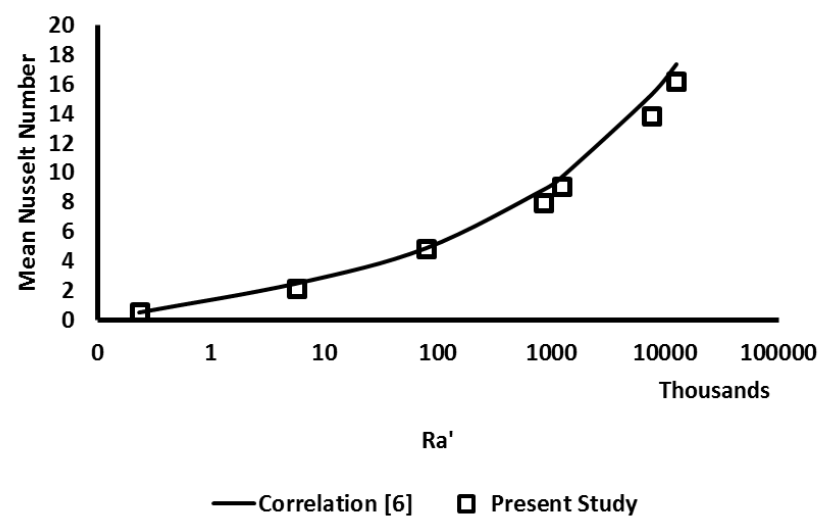

Figure 3: Comparison of obtained numerical results with the results of correlations of BarCohen and Rohsenow [6] for the channel with natural convection 


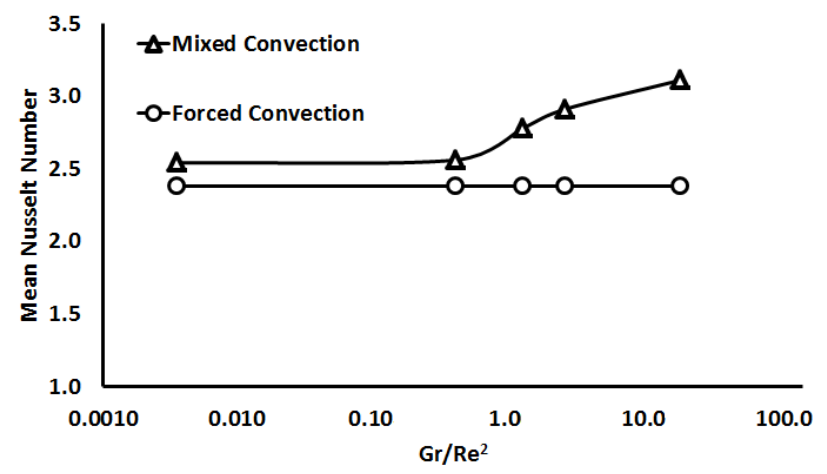

Figure 4: The change of mean Nusselt number with $\mathrm{Gr} / \mathrm{Re}^{2}$ for the channel with mixed convection when entire walls at constant temperature and $\mathrm{H} / \mathrm{w}=16.67$.

Figure 5 shows dimensionless temperature and velocity distributions in the half of channel when $\mathrm{Gr} / \mathrm{Re}^{2}=0.0033$ and 13.33 for completely heated channel. Figure 5(a) represents dimensionless temperature and velocity distributions in the half of a channel whose both walls is completely heated for $\mathrm{Gr}$ $/ \mathrm{Re}^{2}=0.0033$. As can be seen, the velocity profiles for fully developed region are parabolic since buoyancy effect is negligible. Figure 5(b) shows dimensionless velocity and temperature distributions in the same channel of Figure 5(a) when $\mathrm{Gr} / \mathrm{Re}^{2}$ ratio increases to 13.33 . By increasing $\mathrm{Gr} / \mathrm{Re}^{2}$ ratio, the buoyancy effect gains importance and the vertical velocity near the hot wall increases. A reverse flow with low intensity occurs at the center of the channel. The comparison of dimensionless temperature between Figure 5(a) and 5(b) shows that the heat transfer rate in transverse direction for $\mathrm{Gr} /$ $\operatorname{Re}^{2}=13.33$ is greater than that of $\mathrm{Gr} / \mathrm{Re}^{2}=0.0033$ since air in the middle of the channel of Figure 5(a) is cold. Thus, the mean Nusselt number of the channel with $\mathrm{Gr} / \mathrm{Re}^{2}=13.33$ is expected to be greater than that of $\mathrm{Gr} / \mathrm{Re}^{2}=0.0033$

Figure 6 shows the change of the local Nusselt number along the completely heated vertical wall for two cases as $\mathrm{Gr} /$ $\mathrm{Re}^{2}=0.0033$ and $\mathrm{Gr} / \mathrm{Re}^{2}=13.33$. As it can be seen from the Figure 6, the maximum local Nusselt number occurs at the inlet of the channel and it decreases by the distance from the channel inlet. The rate of decrease of the local Nusselt number for the channel with $\mathrm{Gr} / \mathrm{Re}^{2}=0.0033$ is higher as expected. As a result, the mean Nusselt number of the channel with $\mathrm{Gr} /$ $\mathrm{Re}^{2}=13.33$ should be greater than $\mathrm{Gr} / \mathrm{Re}^{2}=0.0033$ for inlet section. In this study, the mean Nusselt number of the completely heated channel for $\mathrm{Gr} / \mathrm{Re}^{2}=0.0033$ is found as 2.54 while for $\mathrm{Gr} / \mathrm{Re}^{2}=13.33$ the value of mean Nusselt number is calculated as 3.11. From practical application point of view, for a fixed Reynolds number ( mass flow rate into channel is reduced by increasing width of the channel and it causes the considerable increase of Grashof number. The increase of width of channel (without changing aspect ratio) increases the length of entrance region and the value of local Nusselt number at the inlet region. Consequently, the increase of width and height of a channel causes the channel is cooled with less air flow rate but provides more high-powered electronic components can be mounted on the walls of channel in the entrance region. It should be mentioned that the increase of local Nusselt number is valid up to a height of channel (for our case $\mathrm{Y}=5$ ).

Figure 7 shows dimensionless temperature and velocity distributions in the partially heated channel with one portion heated when $\mathrm{Gr} / \mathrm{Re}^{2}=0.0033$ and 13.33. Figure 7(a) represents dimensionless temperature and velocity distributions in the half of a channel whose bottom half of the walls are completely heated while the top half of the walls are adiabatic when $\mathrm{Gr} / \mathrm{Re}^{2}=0.0033$. As it is seen, the velocity profile is parabolic and it is not affected from the temperature distribution in the channel. By increasing $\mathrm{Gr} / \mathrm{Re}^{2}$ ratio from 0.0033 to 13.33 , as shown in Figure 7(b), the velocity near the heated portion increases and reverse flow at low intensity in middle of the channel occurs. The buoyancy effect loses its importance after heated portion through to the exit of the channel since the walls are adiabatic in this section. As a result, the flow reversals disappear and parabolic velocity profile starts to be developed.

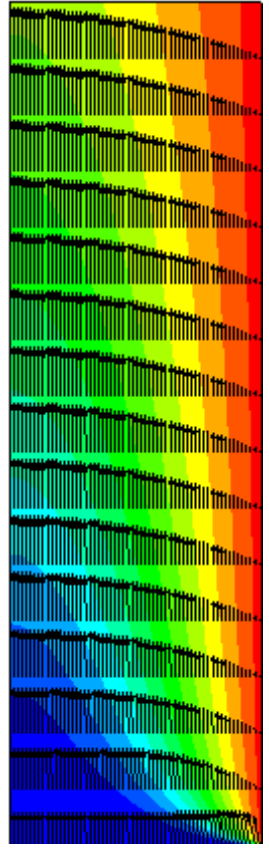

(a)

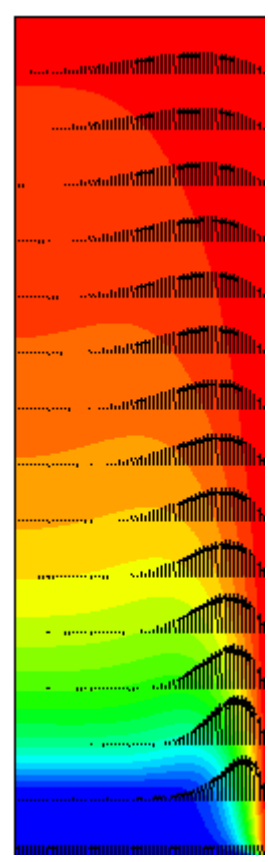

(b)
Figure 5: Dimensionless velocity and temperature distribution in the completely heated channel a) $\mathrm{Gr} / \mathrm{Re}^{2}=0.0033$ b) $\mathrm{Gr} /$ $\operatorname{Re}^{2}=13.33$

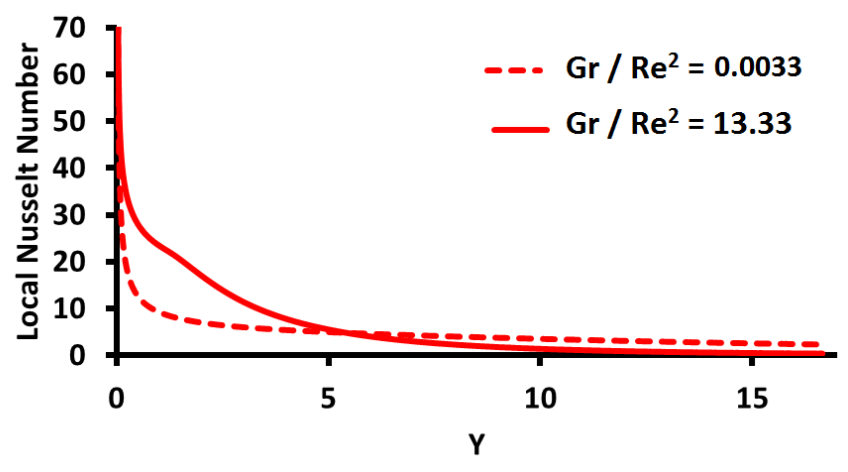


Figure 6: The change of local Nusselt number along a wall of the completely heated channel for $\mathrm{Gr} / \mathrm{Re}^{2}=0.0033$ and 13.33

Figure 8 shows the change of the local Nusselt number along vertical wall of the channel with the one heated portion for two cases as $\mathrm{Gr} / \mathrm{Re}^{2}=0.0033$ and $\mathrm{Gr} / \mathrm{Re}^{2}=13.33$. As expected, the maximum Nusselt number occurs at the inlet of the channel and it decreases along heated portion. The decrease of local Nusselt number along the heated portion of the channel with $\mathrm{Gr} / \mathrm{Re}^{2}=0.0033$ is higher than the channel with $\mathrm{Gr} / \mathrm{Re}^{2}=13.33$. By increasing the distance, the adiabatic wall appears and the Nusselt number becomes zero through the exit of the channel. Similar to the Figure 6, the increase of width and height of the channel cause the increase of entrance region and local Nusselt number in the inlet region.

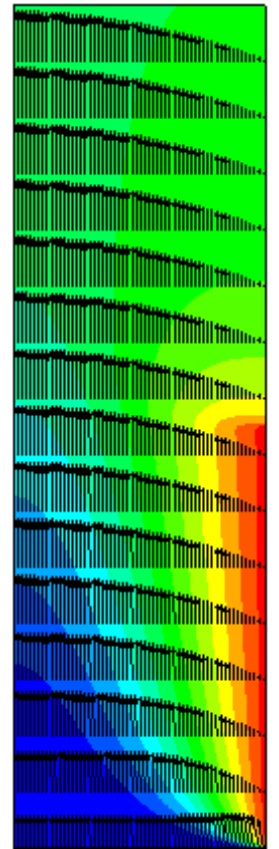

(a)

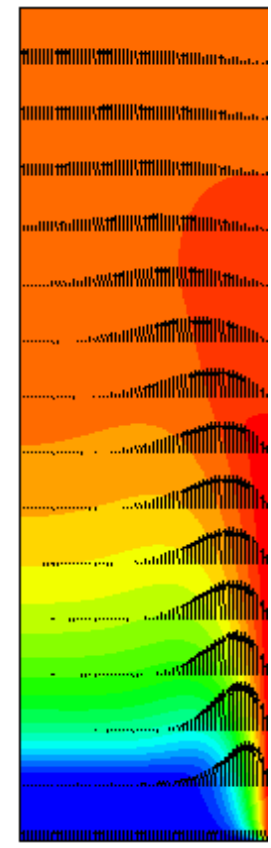

(b)
Figure 7: Dimensionless velocity and temperature distributions in one heated portion channel a) $\mathrm{Gr} / \mathrm{Re}^{2}=$ 0.0033 b) $\mathrm{Gr} / \mathrm{Re}^{2}=13.33$

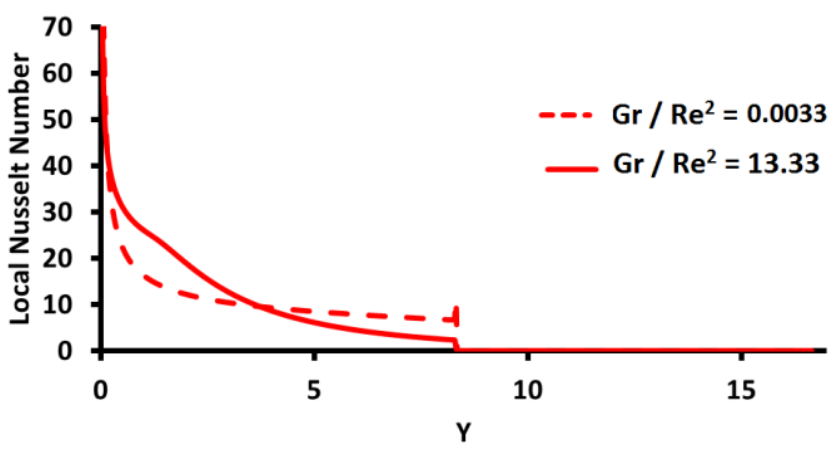

Figure 8: The change of local Nusselt number along a wall of the channel with one heated portion for $\mathrm{Gr} / \mathrm{Re}^{2}=0.0033$ and 13.33

Figure 9 shows dimensionless temperature and velocity distributions in half of channel with two heated portions when $\mathrm{Gr} / \mathrm{Re}^{2}=0.0033$ and 13.33. As it is seen from Figure 9(a), when $\mathrm{Gr} / \mathrm{Re}^{2}=0.0033$, the buoyancy effect is negligible and forced convection is dominant. Thus, the velocity profile is parabolic in the channel. For the channel with $\mathrm{Gr} / \mathrm{Re}^{2}=$ 13.33, as shown in Figure 9(b), the buoyancy effect gains importance in the first quarter section of the channel and velocity near the first heated portion increases. By increasing the distance from the first quarter of the channel through the half of the channel (the wall is adiabatic) the temperature difference is reduced and the effect of buoyancy force decreases. That is why parabolic velocity profile starts to be developed. By starting the second heated portion, the temperature gradient in transverse direction increases and the buoyancy force influences the flow and the velocity near the second heated portion of the wall increases again. The shape of the velocity profile turns to parabolic again in the last quarter of the channel where the wall is adiabatic.

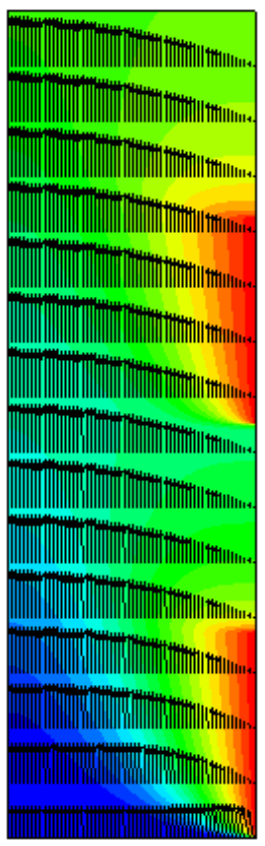

(a)

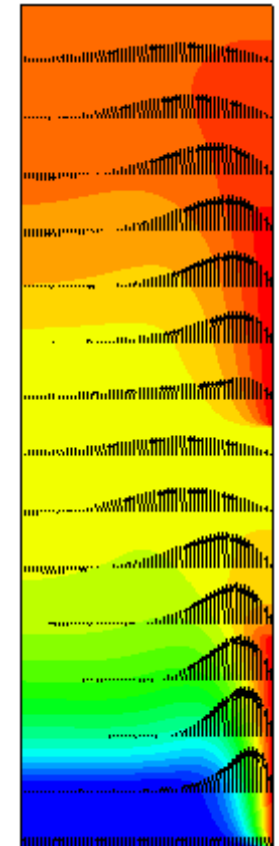

(b)
Figure 9: Dimensionless velocity and temperature distributions in the channels with two heated portions a) $\mathrm{Gr} /$ $\mathrm{Re}^{2}=0.0033$ b) $\mathrm{Gr} / \mathrm{Re}^{2}=13.33$

Figure 10 shows the change of the local Nusselt number along the vertical wall with the two heated portions and for two cases as $\mathrm{Gr} / \mathrm{Re}^{2}=0.0033$ and $\mathrm{Gr} / \mathrm{Re}^{2}=13.33$. Again, the maximum Nusselt number is seen at the inlet section of the channel and the decrease of the Nusselt number for the case of $\mathrm{Gr} / \mathrm{Re}^{2}=0.0033$ is faster than the case of $\mathrm{Gr} / \mathrm{Re}^{2}=13.33$. Then the value of Nusselt number becomes zero at adiabatic section. At the starting of the second heated portion, Nusselt number increases and then it decreases through the end of the 
heated portion. The important point of Figure 10 is that the local Nusselt number is the same for the first and second portions when $\mathrm{Gr} / \mathrm{Re}^{2}=0.0033$. However, for the channel with $\mathrm{Gr} / \mathrm{Re}^{2}=13.33$, heat transfer rate is higher for the first heated portion and become smaller for the second portion. Thus, if two electronic components or set of electronic components located periodically on a wall of a channel, the rate of cooling will be identical for both of them when $\mathrm{Gr} /$ $\mathrm{Re}^{2}$ is small (i.e. Gr / $\mathrm{Re}^{2}=0.0033$ ). By increasing width of the channel (without changing Reynolds number and aspect ratio) three important effects appear: a) the increase of the size channel provides more components mounted in the channel, b) the channel will be cooled by less mass flow rate so fan with smaller power can be used, c) the buoyancy effect increases and the local Nusselt number at the entrance region considerably increases and high-powered components can be located in the first portion. The components with less heat generation can mounted in the second portion.

Figure 11 shows dimensionless temperature and velocity distributions in the channel with four heated portions when $\mathrm{Gr}$ $/ \mathrm{Re}^{2}=0.0033$ and 13.33. As it is seen on Figure 11(a), when $\mathrm{Gr} / \mathrm{Re}^{2}=0.0033$, buoyancy effect does not play an important role and the velocity profile is parabolic in the fully developed region of the channel. When $\mathrm{Gr} / \mathrm{Re}^{2}=13.33$, as shown in Figure 11(b), the buoyancy effect becomes important and the velocity near the region of the first heated portion increases, furthermore a reverse flow occurs in the center of the channel. By increasing the distance from the first heated portion through the second heated portion, which is adiabatic, the temperature gradient in transverse direction is reduced and consequently the buoyance effect becomes negligible. The velocity profile becomes a little flat and tends to be parabolic. However, there is not enough distance to have a developed parabolic velocity profile and that's why the velocity in the region near the second heated portion of the wall increases again. There is a reverse flow in the middle part of the second heated portion. The same behavior is repeated for the third and fourth heated regions.

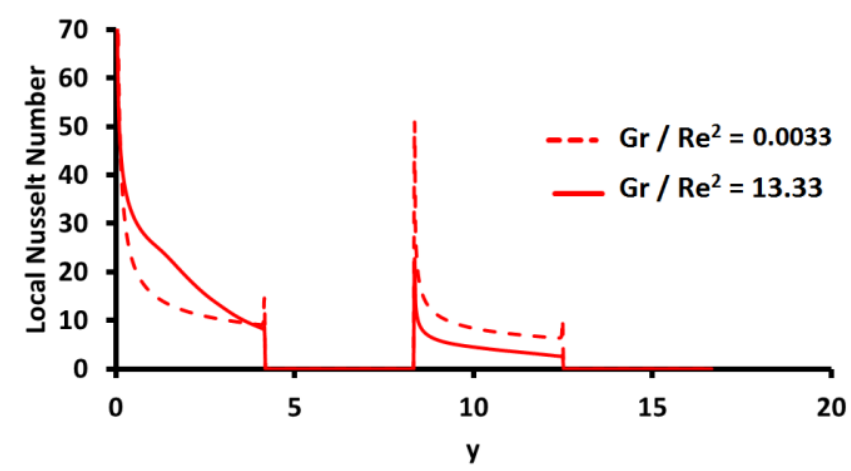

Figure 10: The change of local Nusselt number along a wall of the channel with two heated portions for $\mathrm{Gr} / \mathrm{Re}^{2}=0.0033$ and 13.33

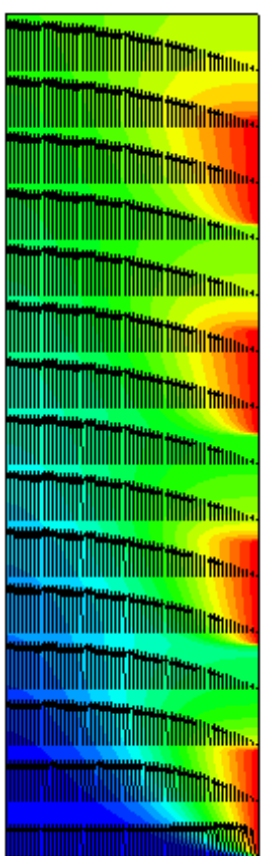

(a)

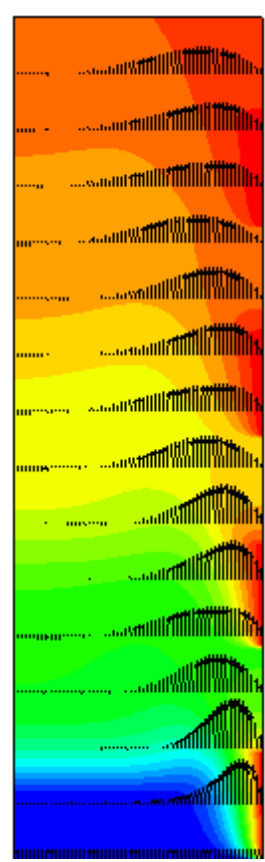

(b)
Figure 11: Dimensionless velocity and temperature distributions in the channels with four heated portions a) $\mathrm{Gr} /$ $\mathrm{Re}^{2}=0.0033$ b) $\mathrm{Gr} / \mathrm{Re}^{2}=13.33$

Figure 12 shows the variation of the local Nusselt number along vertical wall with the four heated portions for two cases as $\mathrm{Gr} / \mathrm{Re}^{2}=0.0033$ and $\mathrm{Gr} / \mathrm{Re}^{2}=13.33$. As it can be seen, the decrease of the local Nusselt number for the channel with $\mathrm{Gr} / \mathrm{Re}^{2}=0.0033$ is greater than that of $\mathrm{Gr} / \mathrm{Re}^{2}=13.33$ for the first heated portion. The values of the local Nusselt number for $\mathrm{Gr} / \mathrm{Re}^{2}=0.0033$ and $\mathrm{Gr} / \mathrm{Re}^{2}=13.33$ are almost the same for the second heated portion. However, the local Nusselt number for $\mathrm{Gr} / \mathrm{Re}^{2}=13.33$ decreases faster than $\mathrm{Gr} /$ $\mathrm{Re}^{2}=0.0033$ for the third heated portion. The same behavior is observed for the fourth heated portion, clearly. Figure 12 shows that the rate of heat transfer by mixed convection in the entrance region of the channel is greater than that by forced convection. However, after the second heated portion, the heat transfer rate by forced convection becomes greater than that by mixed convection. Hence, the same comments explained for Figure 10 is valid for Figure 11.

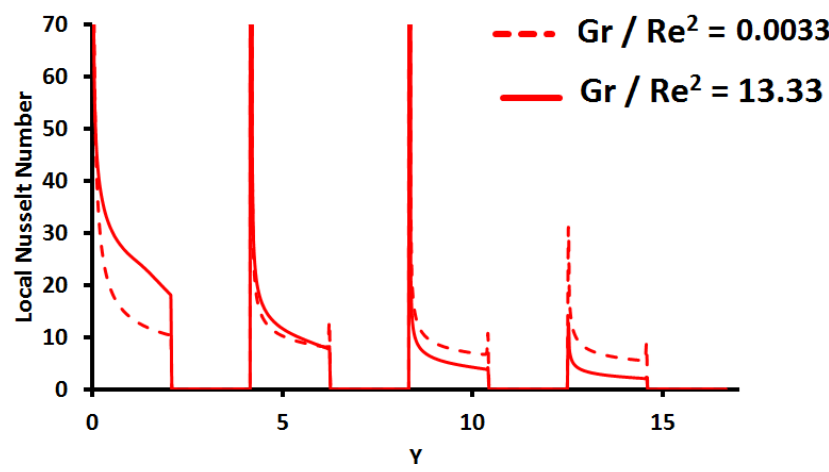


Figure 12: The change of local Nusselt number along a wall of the channel with four heated portions for $\mathrm{Gr} / \mathrm{Re}^{2}=0.0033$ and 13.33

The change of mean Nusselt with number of heated portions for two channels with $\mathrm{Gr} / \mathrm{Re}^{2}=0.0033$ and 13.33 is shown in Figure 13. For the channels with one and two number of heated portions, the mean Nusselt number for $\mathrm{Gr} /$ $\mathrm{Re}^{2}=13.33$ is greater than that of $\mathrm{Gr} / \mathrm{Re}^{2}=0.0033$. However, for the channels with three and four number of heated portions, the mean Nusselt number becomes greater for the channels with dominant buoyancy effect $\left(\mathrm{Gr} / \mathrm{Re}^{2}=\right.$ 13.33). Figure 13 also shows that for both cases (i.e., $\mathrm{Gr} / \mathrm{Re}^{2}$ $=0.0033$ and 13.33), the increase of number of heated portion increases mean heat transfer rate from the channel. Thus, instead of continues location of electronic components on a wall of a channel, periodically location enhances mean heat transfer rate from the channel.

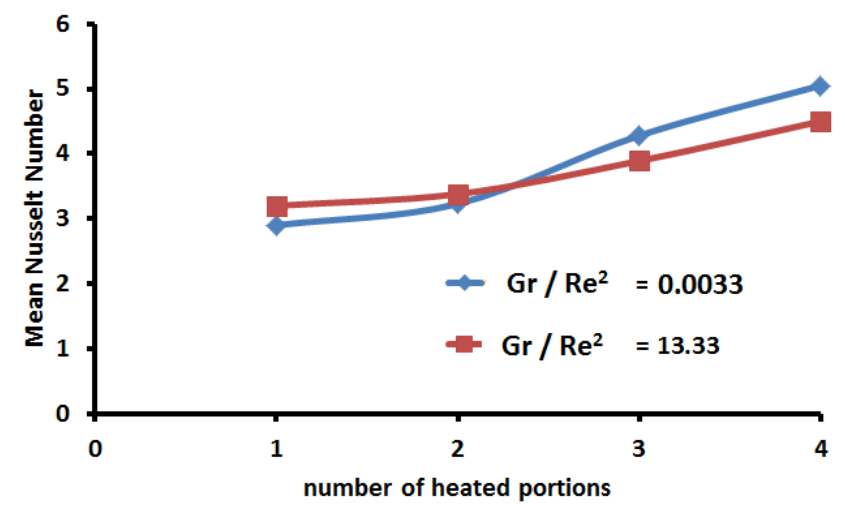

Figure 13: The change of mean Nusselt number with number of heated portions for the studied channels with $\mathrm{Gr} / \mathrm{Re}^{2}=$ 0.0033 and 13.33

\section{CONCLUSION}

Mixed convection heat transfer in a partially and symmetrically heated parallel plate vertical channel is studied numerically. It is observed that, for the channels with multiple heated portions, the velocity near the heated portion increases due to buoyancy effect. After the heated portion, temperature gradient in transverse direction is reduced and a parabolic velocity profile starts to be developed in the adiabatic sections. This behavior is repeated for other regions of the heated portions. The reversal flows occurs in the middle of the channel when buoyancy effect is dominant (i.e. $\mathrm{Gr} / \mathrm{Re}^{2}=$ 13.33).For periodically located electronic components on a wall of channel; the rate of heat transfer is almost the same for all portions when $\mathrm{Gr} / \mathrm{Re}^{2}=0.0033$. However, by increasing the width of the channel without changing Reynolds number and aspect ratio: a) the size of the channel increases and more components can be cooled, b) mass flow rate is reduced and fan with less power and noise can be used, c) buoyancy effect increases and heat transfer rate from the first heated portions considerably increases. High-powered components can be located in the first region and the electronic components with less heat generation can placed in the next portions.
Furthermore, heat transfer rate increases with the increase number of component (or set of components) located periodically on a wall of the channel. Hence, periodical arrangement of components should be preferred to the continuous one.

\section{REFERENCES}

[1] H. Turkoglu, N. Yucel, "Mixed convection in vertical channels with a discrete heat source", vol. 30, pp. 156-166, 1995

[2] L. M. Suestegui, C. Trevino, "Transient laminar opposing mixed convection in a differentially and asymmetrically heated vertical channel of finite length", Int. J. Heat and Mass Transfer, vol. 51, pp. 5991-6005, 2008

[3] D. Elpidorou, V. Prasad, V. Modi, "Convection in Vertical Channel with a Finite Wall Heat Source", Int. J. Heat and Mass Transfer, vol. 34, pp. 573-578, 1991

[4] I. A. Ermolaev, A. I. Zhbanov, "Mixed Convection in Vertical Channel with Discrete Heat Sources at the Wall", Fluid Dynamics, vol. 44, No:4, pp. 511-516, 2009

[5] L. C. Chow, S. R. Husain, A. Campo, "Effects of Free Convection and Axial Conduction on Forced Convection Heat Transfer Inside a Vertical Channel at Low Peclet Numbers", J. Heat Transfer, vol. 106, pp. 297-303

[6] A. Bar-Cohen, W. M. Rohsenow, "Thermally Optimum Spacing of Vertical, Natural Convection Cooled, Parallel Plates", vol. 106, pp. 116-123, 1984For high values of Gr / $\operatorname{Re}^{2}$ (i.e. $\mathrm{Gr} / \mathrm{Re}^{2}=13.33$. 